\title{
Cataract-deafness-hypogonadism syndrome
}

INSERM

\section{Source}

INSERM. (1999). Orphanet: an online rare disease and orphan drug data base. Cataractdeafness-hypogonadism syndrome. ORPHA:1383

Cataract-deafness-hypogonadism syndrome is an extremely rare multiple congenital abnormality syndrome, described in only three brothers to date, that is characterized by the association of congenital cataract, sensorineural deafness, hypogonadism, mild intellectual deficit, hypertrichosis, and short stature. There have been no further descriptions in the literature since 1995. 